\title{
Comparison of the Isotopical Tracer and the Triton WR 1339 Methods for Triglyceride Kinetics in Carbohydrate-fed Rats
}

\author{
Tsutomu Hirano, ${ }^{1}$ John C. L. MAMO ${ }^{2}$ and Terumi TAKAHASHI ${ }^{1}$ \\ ${ }^{1}$ The First Department of Internal Medicine, School of Medicine Showa University, \\ Shinagawa-ku, Tokyo 142 \\ ${ }^{2}$ The Department of Physiology, University of Western Australia, \\ Nedlands 6009, West. Australia
}

(Received April 5, 1990)

Summary Radiolabeled tracer $\left[{ }^{3} \mathrm{H}\right]$ very low density lipoprotein (VLDL)-triglyceride (TG) and non-tracer (Triton WR 1339) methods were used to determine VLDL-TG kinetics in normal rats and in rats given either a $10 \%$ glucose or a $10 \%$ fructose drinking solution for $16 \mathrm{~h}$ ad libitum. The carbohydrate-fed rats were hypertriglyceridemic compared to control animals. VLDL-TG was endogenously prelabeled with $\left[{ }^{3} \mathrm{H}\right]$ glycerol in control, glucose- and fructose-fed rats, and injected into identically treated recipients. Triton WR 1339, a potent inhibitor of VLDL-TG catabolism, was injected into the same animal $30 \mathrm{~min}$ after the end of the tracer method to measure TG secretion rate (TGSR). The tracer and non-tracer methods showed that fructose-fed rats had a significantly lower fractional catabolic rate (FCR) than either control or glucose-fed rats. In contrast, glucose-fed rats had a TGSR greater than control without a reduction in FCR. For all treatments, TG concentration correlated with FCR for the tracer method and with TGSR for the non-tracer method. There was good correlation of TGSR determined by the tracer and non-tracer method for control rats despite the substantial difference in the absolute values. No such relationship was observed in carbohydrate-fed rats. Control rats were made hypertriglyceridemic by Intralipid infusion. A lower FCR was observed when determined by the tracer method, but this was not observed by the triton method. These results suggest that $\mathrm{TG}$ kinetics determined by the tracer and the triton methods cannot be readily correlated, especially in hypertriglyceridemic state. However, the two kinetic studies both suggested that overproduction of VLDL-TG in glucose-fed rats and impaired VLDL-TG catabolism in fructose-fed rats were the primary cause for their hypertriglyceridemia, respectively.

\footnotetext{
1 平野 勉, 高橋昭三
} 
Key Words triglyceride kinetics, glucose, fructose, Triton WR 1339, VLDL-TG turnover.

Secretion rate of very low density lipoprotein (VLDL)-triglyceride (TG) is most frequently determined by one of two techniques in experimental animals in vivo. The first involves the use of Triton WR 1339, which prevents hydrolysis of VLDL-TG by lipoprotein lipase and therefore removal of the lipid per se (1-3). The rate at which TG accumulates within the plasma compartment post Triton WR 1339 administration is then taken to represent the rate of TG entry into the circulation (1-3). TG secretion rate (TGSR) in vivo may also be determined by injecting radiolabeled VLDL-TG, or a precursor of TG such as glycerol, and determining the turnover rate of VLDL-TG under steady-state conditions (4-6). There have been several reports (7-9), including work from our laboratory (10), that have indicated that calculated TGSR may differ substantially depending on which method is employed. Few studies have examined the relationship of TGSR derived by the tracer or the triton methods. Bird et al. (6) reported good agreement of TGSR when determined by the triton method and by monitoring the TG specific activity after a radiolabeled glycerol injection. Conversely, Kannan et al. (9) found that TGSR determined by the injection of endogenous radiolabeled VLDL-TG was considerably higher than the rate determined by the Triton WR 1339 method (8). In addition, qualitative discrepancies arose between treatments as a result of two techniques $(6,8,9)$. Kazumi et al. (11) demonstrated that rats given a $10 \%$ fructose drinking solution for 14 days had a higher TGSR than control rats. However, in a continuation of that study we reported (10) that TGSR in fructosefed rats measured using $\left[{ }^{3} \mathrm{H}\right]$ VLDL-TG did not differ from controls even though the treatment groups were identical to that of Kazumi et al. (11). The contradictory data led us to examine the relationship between the tracer and non-tracer methods of estimating TGSR. To investigate characteristics of two TG kinetic studies, we used acute carbohydrate-fed rats as an experimental animal model. We have reported that a supplementation of glucose or fructose solution as a drinking water for $16 \mathrm{~h}$ elevated plasma TG concentration by either overproduction or catabolic defect of VLDL-TG $(10,12)$. Therefore we thought that acute hexosefed rats would be a useful object to examine the TG kinetics.

It is well established that plasma TG pool could affect efficiency of TG removal in humans (13-15). Unlike humans, little has been known about the pool size effect in rats. To examine this, Intralipid ${ }^{\circledR}$, an artificial TG emulsion, was infused into normal rats and then TG kinetics were carried out under expanded TG pool.

\section{MATERIALS AND METHODS}

Male Wistar rats of body weight 330-360 g (Charles River Japan, Tokyo, Japan) were kept in individual cages on a $12-\mathrm{h}$ light/dark cycle. Control animals 
had free access to rat chow (Oriental Yeast Co. Tokyo, Japan) and water. Carbohydrate-fed rats had chow and either a 10\% fructose or a $10 \%$ glucose drinking solution for $16 \mathrm{~h}$ beginning at the start of the 12-h dark cycle. All rats were deprived of food and drinking solution for two hours before the start of experiments.

Blood was collected by heparinized syringes from the abdominal aorta of rats anesthetized with pentobarbital $(65 \mathrm{mg} / \mathrm{kg}$ i.p.). Plasma was collected after low speed centrifugation. VLDL designated as the density fraction less than $1.006 \mathrm{~g} / \mathrm{ml}$ was isolated as described by Havel et al. (16). VLDL was dialyzed for a minimum of $16 \mathrm{~h}$ against a 1000 -fold excess of phosphate-buffered saline containing $1 \mathrm{~mm}$ EDTA, pH 7.4 at $4^{\circ} \mathrm{C}$. VLDL-TG kinetic studies using radioactive tracer were done as previously described $(10,12,17)$. Briefly, VLDL-TG was endogenously radiolabeled in donor rats using $0.4 \mathrm{mCi}$ of $\left[2{ }^{3} \mathrm{H}\right]$ glycerol $(200 \mathrm{mCi} / \mathrm{mM}, \mathrm{New}$ England Nuclear, Boston, MA). The radiolabeled VLDL-TG (about $0.3 \mathrm{mg}$ TG) from either control, fructose-, or glucose-fed donors was then injected into anesthetized recipient rats which were treated in an identical manner to the donor animals. The decline in the radioactivity was monoexponential $(r>0.96)$ in all turnover studies, thus fractional catabolic rate (FCR) was directly determined from the disappearance curve by a least-square linear regression analysis. TG steady state was assumed if plasma TG concentration 10 min post tracer injection was within $10 \%$ of the preinjection concentration. Validity of this method was described in detail in the previous communications (10). Namely, extrapolation of the disappearance curve to the ordinate (point of injection) showed that the theoretical value of VLDL-TG radioactivity was within 10\% of the actual amount of radioactivity injected. TGSR was calculated as FCR multiplied by the plasma TG pool size [plasma TG concentration in steady state $\times$ assumed plasma volume (4\% of body weight)] $(6,10)$ and expressed in $\mathrm{mg} / \mathrm{min} / 100 \mathrm{~g}$ body weight.

Triton WR 1339 (Sigma Co. St. Louis, MO) $(600 \mathrm{mg} / \mathrm{kg})$ was injected into the femoral vein of recipient rats $30 \mathrm{~min}$ after the final blood sample was taken for the tracer study. In preliminary investigations we found that plasma radioactivity remaining was negligible at this time. Blood samples were collected immediately before Triton WR 1339 administration and 15, 30, and 60 min after injection as previously described (17). TG concentration was found to increase linearly $(r>$ 0.99 ) over the 60 -min period post triton administration. TGSR was calculated as the increment in plasma TG pool per min per $100 \mathrm{~g}$ body weight. FCR in the method was calculated as being TGSR divided by plasma TG pool size (6).

Intralipid infusion study: Normal rats were made hypertriglyceridemic by a constant intravenous infusion of Intralipid, an artificial TG emulsion. Rats were initially anesthetized with pentobarbital $(65 \mathrm{mg} / \mathrm{kg}$ i.p. $)$ and thereafter maintained with hourly injections of pentobarbital at a dose of $25 \mathrm{mg} / \mathrm{kg}$. Intralipid (20\% Intralipos, Green Cross Co. Osaka), was diluted with physiological saline and constantly infused into the femoral vein via cannula at the constant rate of 0.012 $\mathrm{ml} / \mathrm{min}$ by the continuous infusion pump (Matsume Co. Tokyo). We adjused TG 
concentration in the infusate with saline to realize $0.15 \mathrm{mg}$ Intralipid-TG $/ \mathrm{min} / 100 \mathrm{~g}$ body weight. Control animals were infused with physiological saline alone. In preliminary experiments we established that TG reached a new steady state $90 \mathrm{~min}$ after infusion had begun. At $120 \mathrm{~min},\left[{ }^{3} \mathrm{H}\right] \mathrm{VLDL}-\mathrm{TG}$ from chow-fed rats was injected and clearance determined as described above. TGSR was then measured by the triton method $30 \mathrm{~min}$ after the end of the tracer method.

TG concentration in plasma and VLDL was determined enzymatically using a kit that allowed correction for free glycerol (Boehringer-Yamanouchi, Tokyo).

Statistical analyses were performed by analysis of variance and Student- $t$ test to detect differences for three and two groups of rats, respectively. The Pearson's simple linear regression was used to determine the correlation coefficient of two variables.

\section{RESULTS}

Body weight, hexose consumption, and plasma TG concentration for the different treatments are given in Table 1. Body weight was equal for each group and the intake of either fructose or glucose as a $10 \%$ drinking solution was similar for the two hexose groups of rats. Plasma TG concentration was increased in hexose-fed rats: it was about 2 times greater in glucose-fed and 3 times greater in fructose-fed rats than control rats. Most of plasma TG was recovered in a VLDL fraction in all groups; thus hypertriglyceridemia induced by sugar intake was brought about by the increased VLDL-TG concentration.

FCR and TGSR determined by [ ${ }^{3} \mathrm{H}$ ] VLDL-TG (tracer method) or by Triton WR 1339 (non-tracer method) for the different treatments are given in Table 2. FCR and TGSR determined by the tracer method were 3-4 times higher than that derived by the non-tracer method for chow, glucose, and fructose groups. Despite this large quantitative discrepancy, qualitatively there were some similarities between the two different methods. In the glucose-fed rats, FCR was similar to

Table 1. Body weight (BW), sugar intake, and triglyceride concentration in plasma and very low density lipoprotein (VLDL) in control, glucose, and fructose group of rats.

\begin{tabular}{ccccc}
\hline \multirow{2}{*}{$\begin{array}{c}\text { Rat group } \\
(\mathrm{n})\end{array}$} & \multirow{2}{*}{$\begin{array}{c}\text { BW } \\
(\mathrm{g})\end{array}$} & $\begin{array}{c}\text { Sugar intake } \\
(\mathrm{g} / 16 \mathrm{~h})\end{array}$ & \multicolumn{2}{c}{ Triglyceride $(\mathrm{mg} / \mathrm{dl})$} \\
\cline { 4 - 5 } & & & Plasma & VLDL \\
\hline Control (9) & $346 \pm 17$ & $(-)$ & $65 \pm 19$ & $55 \pm 20$ \\
Glucose (9) & $350 \pm 18$ & $12.5 \pm 0.7$ & $124 \pm 32^{* * a}$ & $94 \pm 25^{* * a}$ \\
Fructose (7) & $340 \pm 13$ & $12.3 \pm 1.8$ & $168 \pm 29^{* * \mathrm{*}}$ & $138 \pm 13^{* * \mathrm{~b}}$ \\
\hline
\end{tabular}

Values represent mean \pm standard deviation (SD). Control rats had free access to raw chow and water. Glucose and fructose group of rats had chow and either a $10 \%$ of glucose or fructose drinking solution for $16 \mathrm{~h} .{ }^{*} p<0.05,{ }^{* *} p<0.01$. ${ }^{\text {a }}$ chow vs. glucose; ${ }^{\mathrm{b}}$ chow vs. fructose; ${ }^{\mathrm{c}}$ glucose vs. fructose. 
Table 2. Fractional catabolic rate (FCR) and triglyceride secretion rate (TGSR) determined by the tracer method or the Triton WR 1339 method, in control, glucose, and fructose group of rats.

\begin{tabular}{cccccc}
\hline \multirow{2}{*}{$\begin{array}{c}\text { Rat group } \\
(\mathrm{n})\end{array}$} & \multicolumn{2}{c}{ The tracer method } & & \multicolumn{2}{c}{ The Triton WR 1339 method } \\
\cline { 2 - 3 } \cline { 5 - 6 } & $\begin{array}{c}\mathrm{FCR} \\
\left(\mathrm{min}^{-1}\right)\end{array}$ & $\begin{array}{c}\text { TGSR } \\
(\mathrm{mg} / \mathrm{min} / 100 \mathrm{~g} \\
\mathrm{BW})\end{array}$ & & $\begin{array}{c}\text { FCR } \\
\left(\mathrm{min}^{-1}\right)\end{array}$ & $\begin{array}{c}\text { TGSR } \\
(\mathrm{mg} / \mathrm{min} / 100 \mathrm{~g} \\
\mathrm{BW})\end{array}$ \\
\hline Control (12) & $0.171 \pm 0.056$ & $0.42 \pm 0.13$ & & $0.047 \pm 0.017$ & $0.12 \pm 0.04$ \\
Glucose (13) & $0.153 \pm 0.061$ & $0.60 \pm 0.13^{* * \mathrm{a}}$ & & $0.048 \pm 0.011$ & $0.19 \pm 0.06^{* * \mathrm{a}}$ \\
Fructose (10) & $0.085 \pm 0.027^{* \mathrm{c}}$ & $0.45 \pm 0.08^{* * \mathrm{c}}$ & & $0.033 \pm 0.007^{* * \mathrm{~b}}$ & $0.17 \pm 0.02^{* * \mathrm{~b}}$ \\
\hline
\end{tabular}

The tracer method: $\left[{ }^{3} \mathrm{H}\right]$ VLDL-triglyceride (TG) was injected into rats and subsequent decline in plasma radioactivity with time was used to determine FCR. TGSR was calculated as FCR $\times$ TG pool size (plasma TG concentration $\times$ assumed plasma volume). The Triton WR 1339 method: Thirty minutes after the end of the tracer method, Triton WR $1339(600 \mathrm{mg} / \mathrm{kg})$ was injected into the same rat and subsequently TG concentration was measured in post-triton plasma to determine TGSR. FCR was calculated as TGSR/TG pool. Values represent means \pm SD. ${ }^{*} p<$ $0.05,{ }^{* *} p<0.01$. ${ }^{\text {a }}$ chow vs. glucose; ${ }^{b}$ chow vs. fructose; ${ }^{c}$ glucose vs. fructose.

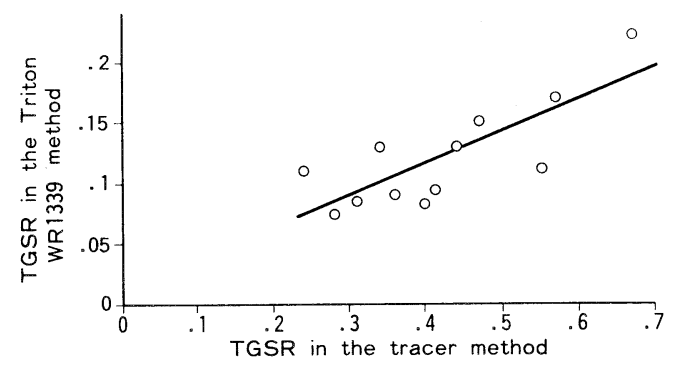

Fig. 1. The relationship between triglyceride secretion rate (TGSR) $(\mathrm{mg} / \mathrm{min} / 100 \mathrm{~g}$ body weight) determined by the $\left[{ }^{3} \mathrm{H}\right]$ very low density lipoprotein-triglyceride injection (tracer method) and the Triton WR 1339 method in the same normal rats. The line indicates a significant correlation $(r=0.78, p<0.005)$ between the two methods.

controls whereas in fructose-fed rats, the FCR was lower than that in control or glucose-fed rats. Both TG kinetic methods demonstrated a higher TGSR in glucose-fed rats when compared to the control group. However, in fructose-fed rats only the triton study suggested that the hypertriglyceridemia was in part due to an overproduction of TG.

As shown in Fig. 1, there was a good correlation of TGSR determined by the tracer and the triton method in the control group of rats $(r=0.78, p<0.005)$ despite the substantial difference in the absolute values. However, in contrast, no such relationship could be established for rats receiving glucose or fructose drinking solutions ( $r=0.18$ and 0.26 , respectively). 
Table 3. Correlation coefficient between plasma triglyceride (TG) concentration and either fractional catabolic rate (FCR) or triglyceride secretion rate (TGSR) determined by the tracer method or the Triton WR 1339 method in control, glucose, and fructose group of rats.

\begin{tabular}{cccccc}
\hline \multirow{2}{*}{$\begin{array}{c}\text { Group } \\
(\mathrm{n})\end{array}$} & \multicolumn{2}{c}{ Tracer method } & & \multicolumn{2}{c}{ Triton WR 1339 method } \\
\cline { 2 - 3 } \cline { 5 - 6 } & FCR & TGSR & & FCR & TGSR \\
\hline Control (12) & $-0.637^{*}$ & $0.599^{*}$ & & -0.439 & $0.816^{* *}$ \\
Glucose (13) & $-0.759^{* *}$ & 0.031 & & -0.351 & $0.742^{* *}$ \\
Fructose (10) & $-0.815^{* *}$ & 0.252 & & -0.474 & $0.710^{*}$ \\
\hline
\end{tabular}

${ }^{*} p<0.05,{ }^{* *} p<0.01$.

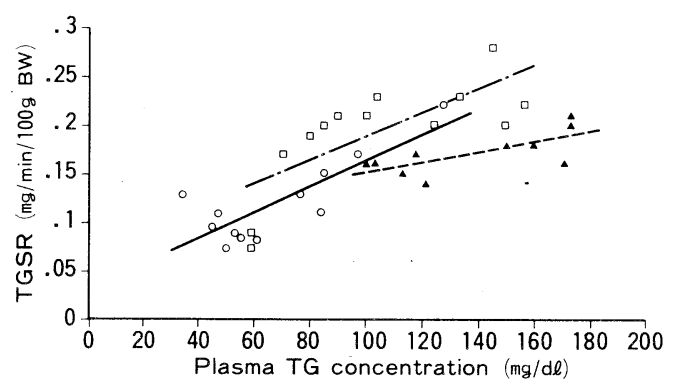

Fig. 2. The relationship between plasma triglyceride (TG) concentration and TG secretion rate (TGSR) determined by the Triton WR 1339 method in control $(-\bigcirc-)$, glucose-fed $(--\square--)$, and fructose-fed $(\cdots \mathbf{- \cdots})$ rats. Correlation coefficient in each line is indicated in Table 3.

We examined the relationship of plasma TG concentration with FCR and TGSR for the two methods to resolve which of these two parameters most regulated plasma TG pool (Table 3 ).

For the tracer study, TG concentration correlated significantly with the rate of VLDL-TG removal. This was even more pronounced for the carbohydrate-fed rats, where the plasma TG pool was increased. Plasma TG concentration was increased with TGSR only in the control group of rats. Conversely, the non-tracer method demonstrated that TG concentration was critically regulated by TGSR in all treatments. The relationship between plasma TG concentration and TGSR determined by the triton method in each group is depicted in Fig. 2. Although the concentration of TG correlated strongly with TGSR in all treatments, the slope of these lines differed. The line depicting the fructose-fed rats was less steep $(y=0.515$ $\left.\times 10^{-3} \mathrm{X}+0.100\right)$ than that representing the control $\left(\mathrm{y}=1.308 \times 10^{-3} \mathrm{X}+0.032\right)$ or glucose groups $\left(y=1.204 \times 10^{-3} X+0.067\right)$. It was particularly interesting to note that at a plasma TG concentration greater than $100 \mathrm{mg} / \mathrm{dl}$, TGSR in the fructosefed rats was significantly lower than in the glucose group $[(0.17 \pm 0.02(n=10)$ and $0.22 \pm 0.03 \mathrm{mg} / \mathrm{min} / 100 \mathrm{~g}$ body weight $(n=7)$, respectively, $p<0.01)]$. 
Table 4. Effect of Intralipid infusion on plasma triglyceride (TG) kinetics determined by the tracer method or the Triton WR 1339 method in control rats.

\begin{tabular}{|c|c|c|c|c|c|}
\hline \multirow[b]{2}{*}{$\begin{array}{l}\text { Infusate } \\
(\mathrm{n})\end{array}$} & \multirow{2}{*}{$\begin{array}{c}\text { Plasma TG } \\
\text { in steady } \\
\text { state } \\
(\mathrm{mg} / \mathrm{dl})\end{array}$} & \multicolumn{2}{|c|}{ The tracer method } & \multicolumn{2}{|c|}{ The Triton WR 1339 method } \\
\hline & & $\begin{array}{c}\text { FCR } \\
\left(\min ^{-1}\right)\end{array}$ & $\begin{array}{c}\text { TGSR } \\
(\mathrm{mg} / \mathrm{min} / \\
100 \mathrm{~g} \mathrm{BW})\end{array}$ & $\begin{array}{c}\text { FCR } \\
\left(\min ^{-1}\right)\end{array}$ & $\begin{array}{c}\text { TGSR } \\
(\mathrm{mg} / \mathrm{min} / \\
100 \mathrm{~g} \mathrm{BW})\end{array}$ \\
\hline Saline (4) & $86 \pm 42$ & $0.192 \pm 0.087$ & $0.61 \pm 0.18$ & $0.051 \pm 0.032$ & $0.15 \pm 0.06$ \\
\hline Intralipid (6) & $262 \pm 35^{* *}$ & $0.102 \pm 0.020^{*}$ & $1.08 \pm 0.32^{*}$ & $0.031 \pm 0.003$ & $0.33 \pm 0.07^{* *}$ \\
\hline
\end{tabular}

Either saline $(0.15 \mathrm{M} \mathrm{NaCl})$ or Intralipid $(0.15 \mathrm{mg} \mathrm{TG} / \mathrm{min} / 100 \mathrm{~g}$ body weight $(\mathrm{BW}))$ was infused into control rats at the constant rate of $0.012 \mathrm{ml} / \mathrm{min}$. The tracer method was performed $120 \mathrm{~min}$ after the beginning of infusion and Triton WR 1339 (600 $\mathrm{mg} / \mathrm{kg} \mathrm{BW}$ ) was injected $30 \mathrm{~min}$ after the end of the tracer method. Plasma TG concentration at steady state was assumed as the mean TG concentration of 90-, $120-$, and 160-min samples after the infusion. Values represent means \pm SD. $*_{p}<$ $0.05,{ }^{*} p<0.01$. Saline infusion vs. Intralipid infusion.

The hypertriglyceridemia exhibited in the carbohydrate-fed rats may have altered the validity of either or both of the TG kinetic methods examined. To study the effect of TG pool size we infused normal rats with Intralipid and measured FCR and TGSR at a constant but elevated concentration of plasma TG. Steady state was achieved $90 \mathrm{~min}$ after infusion of Intralipid had begun and was defined as constant if variability was within a 10\% flux between $90-160 \mathrm{~min}$. The FCR and TGSR of rats infused with Intralipid or saline alone are given in Table 4. Intralipid infused at $0.15 \mathrm{mg} \mathrm{TG} / \mathrm{min} / 100 \mathrm{~g}$ body weight increased plasma TG concentration approximately threefold. FCR calculated by the tracer method was significantly reduced at the elevated plasma TG concentration, but not significantly reduced according to the triton method. TGSR determined using triton $(0.33 \mathrm{mg} / \mathrm{min} / 100$ $\mathrm{g}$ body weight) was identical to the sum of endogenous TG secretion $(0.15$ $\mathrm{mg} / \mathrm{min} / 100 \mathrm{~g})$ and the rate of exogenous TG infused $(0.15 \mathrm{mg} / \mathrm{min} / 100 \mathrm{~g})$. However, TGSR calculated by the tracer method $(1.08 \mathrm{mg} / \mathrm{min} / 100 \mathrm{~g})$ was somewhat higher than the sum of endogenous TG secretion $(0.61 \mathrm{mg} / \mathrm{min} / 100 \mathrm{~g})$ and exogenous lipid infused $(0.15 \mathrm{mg} / \mathrm{min} / 100 \mathrm{~g})$.

\section{DISCUSSION}

The entry rate of TG is frequently determined by Triton WR 1339, which completely blocks hydrolysis of VLDL-TG (3). The subsequent accumulation of plasma TG is considered to reflect the input of newly synthesized VLDL-TG $(1,3$, $7,8,11,17)$.

In the non-tracer study, FCR could be calculated as TGSR/TG pool (6). On the other hand, clearance of TG can be directly determined by monitoring the decline of the injected radioactive tracer in plasma circulation. Endogenous radiolabeled VLDL-TG with glycerol or free fatty acid is usually chosen as the 
tracer $(4-7,9,10,17)$. If the TG concentration remains constant during the TG clearance study, then by definition secretion must equal removal and so TGSR can be determined as FCR multiplied by the plasma TG pool size. Whilst both tracer and non-tracer techniques have been used widely in studying TG kinetics in rats, work from our laboratory and others have experienced difficulties in reconciling data derived by the two methods (6-11).

In control rats, TGSR determined by the triton method was approximately $0.15 \mathrm{mg} / \mathrm{min} / 100 \mathrm{~g}$ body weight. TGSR calculated by the tracer kinetics is about $0.5 \mathrm{mg} / \mathrm{min} / 100 \mathrm{~g}$. The respective values are in good agreement with that published by other laboratories $(4,5,7-9,11,18)$. Because we measured TGSR in the same rat using both tracer and non-tracer techniques, a big magnitude difference between the two techniques would not be due to the difference of individual animals. A possible explanation for a big difference in the TGSR values may be because Triton WR 1339 does not permit TG hydrolysis, thus recycling and incorporation of fatty acids into the liver would be inhibited, which may reduce the part of hepatic TG release which depends on plasma free fatty acid. Palmer et al. (7) demonstrated that about $80 \%$ of newly secreted TG from liver recycles. They suggested that because triton blocks this efflux, TGSR would be underestimated. In contrast, Bird et al. (6) developed a compartmental model for determining FCR and TGSR based on the appearance of radiolabeled TG post radioactive glycerol administration. They showed that the calculated TGSR and FCR were similar to their previous data using Triton WR 1339. Therefore, further study is needed to compare the $\left[{ }^{3} \mathrm{H}\right]$ VLDL-TG injection method and the direct radioglycerol injection method described by these authors in rats, which has been already examined in humans and a good agreement has been observed (15).

Despite the large differences in FCR and TGSR calculated by the two techniques, both methods gave qualitatively some similar results. Rats receiving glucose had a higher TGSR than control animals whilst rats receiving fructose had a significantly lower rate of VLDL-TG removal (Table 2). In addition, there was a good correlation for estimating TGSR between the two techniques in control rats (Fig. 1). However, this correlation was not observed in the hexose-induced hyperlipidemic animals. The tracer method suggested that plasma TG concentration was principally regulated by its rate of removal. This confirms previous work by us and others, in rats $(10,19)$. In addition, it appeared that clearance became of greater importance with increasing levels of plasma TG. Alternatively, this suggests that FCR determined by the tracer method is affected by TG pool size. If TG removal system has saturable process in rats, like humans (13-15), then expanded plasma TG pool would reduce efficiency of TG removal. On the other hand, the triton experiments demonstrated that plasma TG concentration was more closely correlated with TGSR than with FCR in all groups of rats. This lets us speculate that measurement of TGSR by the triton method has some similarity to measure TG output by the liver perfusion system in which TG concentration in the perfusate is principally regulated by TG secretion from the liver. It has been 
reported that in perfused liver, TG secretion was increased in fructose-fed rats (20). We obtained the similar result when TGSR was determined by the triton method, but this was not found in the tracer method. The reasons for the conflicting results remain open to speculation, but if pool size (which is expanding as in fructose-fed rats) influences the rate of clearance, TG kinetics determined by the two methods may differ from each other. Because the triton-administrated animal represents one of an absolute catabolic defect, the pool size effect may not be reflected in this TG kinetics. In spite of the conflicting results about TGSR, the triton study also suggested that the catabolism of TG was impaired in fructose-fed rats because these rats had a relatively small TGSR corresponding to their remarkably elevated plasma TG concentrations (Fig. 2).

To examine whether clearance of VLDL-TG could be impeded due to an expanded TG pool in rats, we elevated the plasma TG levels in normal rats by infusing Intralipid and determined FCR and TGSR using both the tracer and non-tracer techniques. FCR derived by the tracer technique decreased as a result of the increased TG pool size. Kissebah et al. (15) infused humans with intralipid and observed the similar result. These experiments suggest that TG removal is saturable in rats as well as humans. In the present study, TGSR was increased in proportion to the rate of Intralipid-TG infusion in spite of lowering FCR. Plasma TG concentration plateaued at approximately $250 \mathrm{mg} / \mathrm{dl}$ yet $\mathrm{TG}$ remained to be cleared in the first-order kinetics. These kinetical profiles demonstrate that to saturate TG removal, the concentration of plasma TG must exceed $250 \mathrm{mg} / \mathrm{dl}$. The new TG steady state obtained $(250 \mathrm{mg} / \mathrm{dl})$ was significantly higher than the plasma concentration in fructose-fed rats, suggesting that the TG removal system in these animals is not saturated. Therefore the low FCR in these rats may not be exclusively due to the pool size effect, but in part due to an absolute defect of TG catabolism. With the triton method, TGSR was also increased in proportion to the exogenous lipid infused. However, there was no significant corresponding reduction in FCR. This may support the hypothesis that the pool size effect may not be involved in the triton method as described above. TGSR determined by the tracer method was somewhat higher than the sum of endogenous and exogenous TG entry. This could be explained that free fatty acids would increase after intralipid infusion and endogenous TG production may be stimulated by the increment of the fatty acids efflux. On the other hand, free fatty acids derived from Intralipid-TG would be reduced after administration of Triton WR 1339 because the triton suppresses the hydrolysis of the infused TG emulsion completely (21).

In conclusion, the common methods used for determining TGSR and clearance have been compared in normal and carbohydrate-induced hypertriglyceridemic rats. Both the tracer and the non-tracer methods suggested that overproduction of VLDL-TG in glucose-fed rats and an impaired VLDL-TG catabolism in fructose-fed rats were the primary contributing factor to the hypertriglyceridemia respectively. The major difference between the two techniques which remains to be resolved is the substantially different quantitative values of TGSR derived. 


\section{REFERENCES}

1) Otway, S., and Robinson, D. S. (1967): The use of a non-ionic detergent (Triton WR 1339) to determine rates of triglyceride entry into the circulation of the rat under different physiological conditions. J. Physiol. (London), 190, 321-332.

2) Borensztajn, J., Rone, M. S., and Kotlar, T. J. (1976): The inhibition in vivo of lipoprotein lipase (cleaning-factor lipase) activity by the Triton WR-1339. Biochem. J., 156, 539-543.

3) Steiner, G., Haynes, F. J., Yoshino, G., and Vranic, M. (1984): Hyperinsulinemia and in vivo very low-density lipoprotein triglyceride kinetics. Am. J. Physiol., 246 (Endocrinol. Metab. 9), E187-E192.

4) Gregg, R., Mondon, C. E., Reaven, E. P., and Reaven, G. M. (1976): Effect of acute uremia on triglyceride kinetics in the rat. Metabolism, 25, 1557-1565.

5) Van Tol, A. (1977): Hypertriglyceridemia in the diabetic rat. Atherosclerosis, 26, 117-128.

6) Bird, M., Williams, M. A., and Baker, N. (1984): Triacylglycerol secretion in rats: Validation of a tracer method employing radioactive glycerol. J. Nutr., 114, 19781985.

7) Palmer, J. F., Cooper, C., and Shipley, R. A. (1978): Rate of release of hepatic triacylglycerol into serum in the starved rat. Biochem. J., 172, 219-226.

8) Bird, M. I., and Williams, M. (1982): Triacylglycerol secretion in rats: Effects of essential fatty acids and influence of dietary sucrose, glucose or fructose. J. Nutr., 112, 2267-2278.

9) Kannan, R., Baker, N., and Bruckdorfer, K. R. (1981): Secretion and turnover of very low density lipoprotein triacylglycerol in rats fed chronically diets rich in glucose and fructose. J. Nutr., 111,1216-1223.

10) Hirano, T., Mamo, J., Poapst, M., and Steiner, G. (1988): Very low density lipoprotein triglyceride kinetics in acute and chronic carbohydrate fed rats. Am. J. Physiol., 255 (Endocrinol. Metab. 18), E236-E240.

11) Kazumi, T., Vranic, M., and Steiner, G. (1986): Triglyceride kinetics: Effect of dietary glucose, sucrose, of fructose alone or with hyperinsulinemia. Am. J. Physiol., 250 (Endocrinol. Metab. 13), E325-E330.

12) Hirano, T., Mamo, J. C. L., Poapst, M., Kuksis, A., and Steiner, G. (1989): Impaired very low density lipoprotein triglyceride catabolism in acute and chronic fructose fed rats. Am. J. Physiol., 256 (Endocrinol. Metab. 19), E559-E565.

13) Nikkila, E. A., and Kekki, M. (1971): Polymorphism of plasma triglyceride kinetics in normal human adult subjects. Acta Med. Scand., 190, 49-59.

14) Brunzell, J. D., Hazzard, W. R., Porte, D., and Bierman, E. L. (1973): Evidence for a common, saturable, triglyceride removal mechanism for chylomicrones and very low density lipoproteins in man. J. Clin. Invest., 52, 1578-1585.

15) Kissebah, A. H., Adams, P. W., and Wynn, V. (1974): Plasma free fatty acid and triglyceride transport kinetics in man. Clin. Scie. Mole. Med., 47, 259-278.

16) Havel, R. J., Eder, H. A., and Bragdon, J. H. (1955): The distribution and chemical composition of ultracentrifugally separated lipoproteins in human serum. J. Clin. Invest., 34, 1345-1353. 
17) Furukawa, S., Hirano, T., Mamo, J. C. L., Nagano, S., and Takahashi, T. (1990): Catabolic defect of triglyceride is associated with abnormal VLDL in experimental nephrosis. Metabolism, 39, 101-107.

18) Reaven, G. M., Risser, T. R., Chen, Y-D. I., and Reaven, E. P. (1979): Characterization of a model of dietary-induced hypertriglyceridemia in young, nonobese rats. $J$. Lipid. Res., 20, 371-378.

19) Nikkila, E. A., and Ojala, K. (1966): Acute effects of fructose and glucose on the concentration and removal rate of plasma triglyceride. Life Sci., 5, 89-94.

20) Schonfeld, G., and Pfleger, B. (1971): Utilization of exogenous free fatty acids for the production of very low density lipoprotein triglyceride by livers of carbohydrate-fed rats. J. Lipid. Res., 12, 614-621.

21) Hirata, M. H., Oliveira, H. C. F., Quintao, E. C. R., and Redgrave, T. G. (1987): The effects of Triton WR-1339, protamine sulfate and heparin on the plasma removal of emulsion models of chylomicrons and remnants in rats. Biochim. Biophys. Acta, 917, 344-346. 